\title{
Static and Buckling Analysis of Concrete Spherical
}

\section{Shells}

\author{
Ivana Mekjavić \\ Faculty of Civil Engineering, University of Zagreb, Zagreb 10000, Croatia
}

\begin{abstract}
A finite element analysis, including static and buckling analysis is presented for several notable concrete spherical shells around the world. Also, the structural optimization study of these shells was performed for thickness distribution and structure shape to reduce overall tensile stress, deflection and reinforcements. The finite element analysis using Sofistik software shows that a distributed concrete thickness reduces shell stresses, deflections and reinforcements. A geometrically non-linear analysis of these structures with and without imperfections was also performed. To take into account the possible plastification of the material an analysis with non-linear material was performed simultaneously with the geometrically non-linear analysis. This helps in developing an understanding of the structural behaviour and helps to identify all potential failure causes using failure analysis.
\end{abstract}

Key words: Static analysis, buckling analysis, structural optimization, concrete shells, spherical shells.

\section{Introduction}

Using the Sofistik finite element program [1] that solves large-scale structural analysis problems, several spherical shell structures were examined. Figs. 1-3 show some of the remarkable early shells for the Kresge - MIT (Massachusetts Institute of Technology) Auditorium in Boston, Ehime Public Hall in Matsuyama and Het Evoluon in Eindhoven.

Kresge - MIT Auditorium designed by a noted modernist architect, Eero Saarinen, consists of a one-eighth spherical segment dome-shaped concrete roof enclosing a triangular area approximately $49 \mathrm{~m}$ (160 ft) on a side. The dome is entirely supported on three points at the vertices of the triangle. The total weight of the roof is approximately 1500 tons, and the thickness of the roof shell is $8.9 \mathrm{~cm}$ (3.5 in.) which is increased near the edge beams up to $14 \mathrm{~cm}$. The $8.9 \mathrm{~cm}$ (3.5 in.) concrete shell is covered with $5.1 \mathrm{~cm} \mathrm{(2} \mathrm{in.)} \mathrm{of}$ glass fiberboard and a second non-structural layer of lightweight concrete $5.1 \mathrm{~cm}$ (2 in.) thick. Additions had to be made to this structure, since Saarinen's sculptural

Corresponding author: Ivana Mekjavić, $\mathrm{PhD}$, assistant professor, research field: concrete structures, durability and dynamic effects/vibrations. E-mail: ivanam@grad.hr. cutting of the shell created severe edge disturbances to the membrane stresses in the shell that had to be counteracted by an edge beam $45.7 \mathrm{~cm}$ (18 in.) height. There were also large stresses created at the three points of support. These were reinforced with tapered $\mathrm{H}$-shaped steel ribs, which in turn were connected to a steel hinge allowing for movement. In the end, after the formwork was removed it was discovered that the edges were deflecting an unacceptable amount (clearly well over $12.7 \mathrm{~cm}$ (5 in.)) due to uncontrolled creep. Additional supports were added in the form of (4 in. $\times 9$ in.) steel tubes spaced at $3.35 \mathrm{~m}(11 \mathrm{ft})$, which are also used to support the window wall [2].

The problems with this building did not end with the resolution of the structural problems. The shell was difficult and unusual to construct, and significant difficulties were encountered in concrete placement (poor consolidation), protection of the reinforcing steel (inadequate concrete cover) and above all in the waterproofing the roof of the building. The satisfactory resolution of these problems had to wait until decades after the commissioning of the building and through several trials of different roofing procedures. The original neoprene roofing was later replaced with 


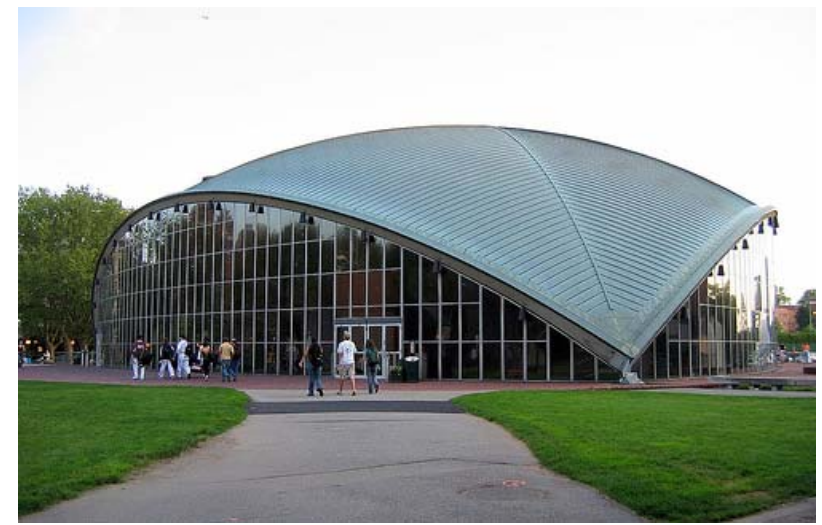

Fig. 1 Kresge - MIT Auditorium, Boston, USA (Saariner, 1954).

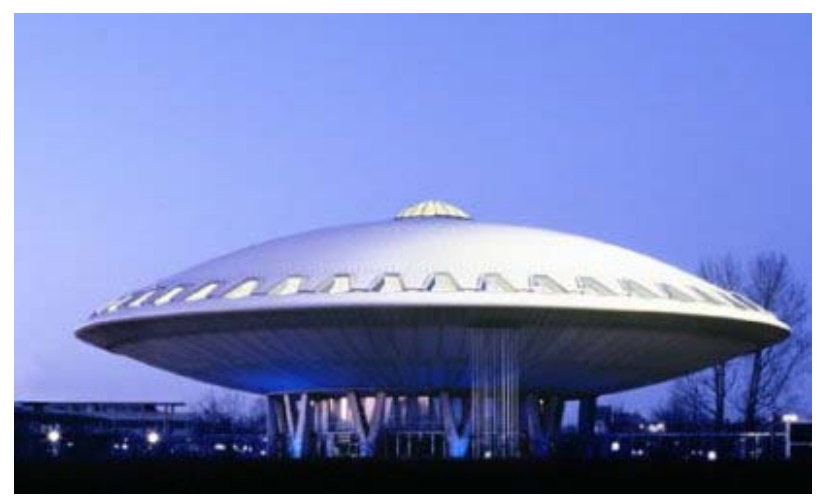

Fig. 2 Het Evoluon, Eindhoven, Netherlands (Kalff, 1966).

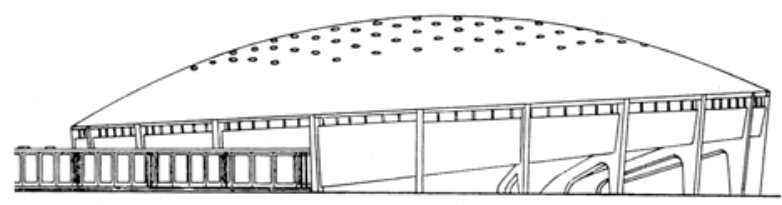

Fig. 3 Ehime Public Hall, Matsuyama, Japan (Tange\&Tsuboi) [3].

lead-coated copper roofing and then copper roofing. The repair of the construction was costly and forced the closure of the building for a few months.

The Ehime Public Hall in Matsuyama, Japan, designed by Japanese engineers, Tange and Tsuboi, is a shallow spherical inclined shell supported by 20 columns. A ring is provided around the base between columns. The thickness of the shell is $8 \mathrm{~cm}$ with a diameter of $49.35 \mathrm{~m}$ and a rise of $7 \mathrm{~m}$ at the crown [3].

The Het Evoluon in Eindhoven was the last major project of the Netherlands designer Louis Kalff. The building is unique due to its resemblance to a landed flying saucer, which makes it look very futuristic. The dome has a diameter of $77 \mathrm{~m}$ and rests on $12 \mathrm{~V}$-shaped columns. The overall height of the building is $30 \mathrm{~m}$ [3].

\section{Structural Optimization Study}

The optimization studies on these structures fall into three categories: (1) a thickness optimization study that compares a shell with uniform thickness to one in which the thickness is optimally distributed over the area, (2) a size optimization study that examines the size of the edge beam and (3) a material optimization study. The maximum compressive and tensile stresses and maximum deflections are evaluated. The maximum compressive stresses are not discussed but shown to be well within the limits of concrete strength except for the original design of the Kresge Auditorium (Fig. 1). However, during repair of the Kresge Auditorium the strength of the concrete was found to be well above the required strength, ranging from 31 to $38 \mathrm{MPa}$ (4,500 to $5,500 \mathrm{psi})$ [4].

The concrete material properties assume a unit weight of $25 \mathrm{kN} / \mathrm{m}^{3}$, a Young's Modulus of $36 \mathrm{GPa}$ $(\mathrm{C} 45 / 55)$ and a Poisson's ratio of 0.2. The reinforcing steel material properties assume a yield strength of 500 MPa and a Young's Modulus of $200 \mathrm{GPa}$. The load on the structure is its self weight and snow load of 1.25 $\mathrm{kN} / \mathrm{m}^{2}$ uniformly distributed on the horizontal projection.

In Sofistik FEA program, the Sofiplus was used as pre-processing tool for model building and mesh generation. The quadrilateral or triangular element (in the case of MIT Auditorium) was used in meshing.

\subsection{Thickness Optimization}

The distribution of thickness was obtained via free optimization. Free optimization refers to determine the thickness of the shell free hand, that is, without a computer algorithm.

It is assumed that each element of the mesh for Kresge Auditorium has the same initial thickness equal to $8 \mathrm{~cm}$. The program Bemess in Sofistik carried out the task of reinforcement design according to Eurocode 
2, Part 1 [5]. The criterion for thickness optimization was the punching design performed by Bemess. The optimum solution of the design task shows a clear distribution of larger thickness around the supports equal to $30 \mathrm{~cm}$ (Fig. 4). The colors represent the gradation of thickness.

The deflections and maximum tensile stresses of the shell with an optimized thickness distribution (Design 2) are compared to the same shell with a uniform thickness of $8.9 \mathrm{~cm}$ (original Design 1) and another distributed thickness shell with edge beam of uniformly varying cross section (Design 3 ).

In the original Design 1, the concrete shell is reinforced with a stiffening beam $(20 \mathrm{~cm} \times 45 \mathrm{~cm})$ around the perimeter of the building, and the concrete class is C30/37. In the Design 2 the concrete strength of the distributed thickness shell and $20 \mathrm{~cm} \times 45 \mathrm{~cm}$ edge beam is $\mathrm{C} 40 / 50$. The Design 3 comprises distributed thickness shell and $(30 \mathrm{~cm} \times 30 \mathrm{~cm}$ to $30 \mathrm{~cm} \times 70 \mathrm{~cm})$ edge beam with higher concrete strength $\mathrm{C} 45 / 55$.

The maximum tensile principal stresses (loadcase dead load) are equal to $14.44 \mathrm{MPa}, 3.89 \mathrm{MPa}$ and 2.77 MPa for Design 1, Design 2 and Design 3, respectively.

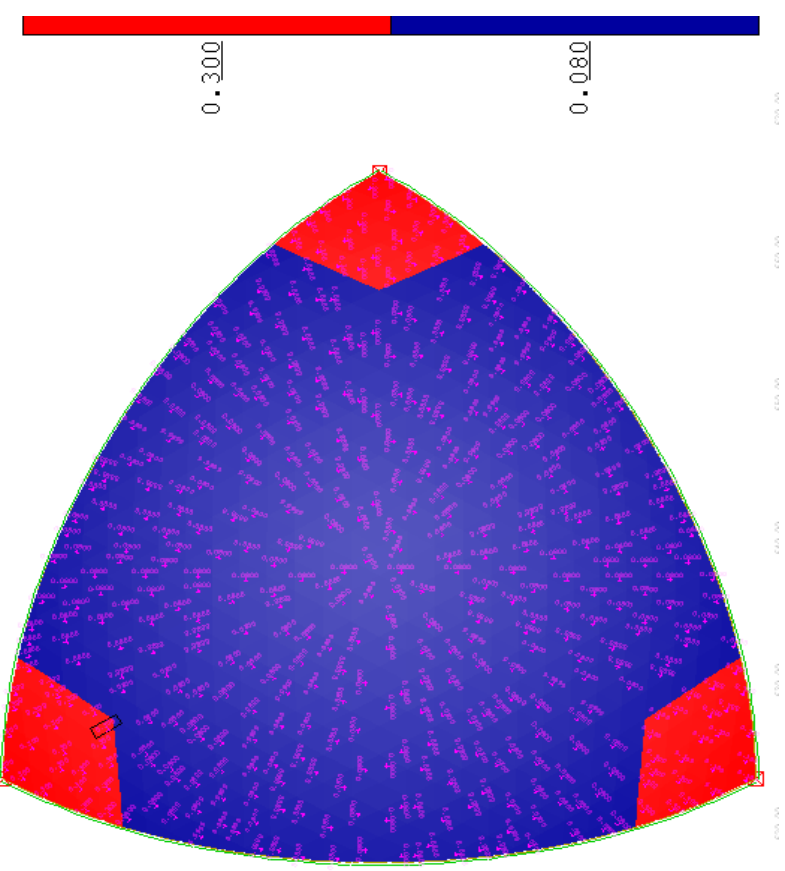

Fig. 4 Structural optimization design for Kresge Auditorium.
These maximum tension stresses occur in the region of the supports, gradually decreasing to zero at the center of the shell.

Fig. 5 shows the areas of tension maximum principal stresses for the three shell designs. The figures clearly show that Design 3 develops less tensile area and smaller maximum tension stresses, and thus is a more efficient design.

The deflections of the shell reflect stiffness and safety. Heinz Isler, respected designer of thin shell concrete structures, set a maximum accepted deflection to span ratio $(\Delta / L)$ equal to $1 / 300$ for his shells [6]. This value can be used as a reference for examining the maximum downward deflection in this shell, which occurs at the high point of the side span $L$ (Fig. 6). The $\Delta / L$ values are equal to $1 / 164,1 / 973$, and $1 / 1,340$ for Design 1, Design 2 and Design 3, respectively. These ratios, except for Design 1, are significantly smaller than that imposed by Isler [6]. In addition, it is seen that the deflections for the distributed thickness shells (Designs 2 and 3) are much smaller than the uniform thickness shell (Design 1).

Examination of the contours of maximum downward displacement shows that the uniform thickness of 8,9 $\mathrm{cm}$ shell has not only a larger maximum, but that maximum extends over a greater area than the other two shells.

\subsection{Size and Material Optimization}

The effects of the beam size and material properties for the Kresge shell were also obtained via free optimization. The design variables that are changed are the height of the edge beam, and the concrete strength. The edge beam of uniformly varying cross section (height varies from $30 \mathrm{~cm}$ at apex to $70 \mathrm{~cm}$ at supports) in Design 3 enhances the shell stiffness, reducing maximum (principal) tensile stresses and deflection, and thereby reducing reinforcements (Table 1). Also, the higher concrete strength of $C 45 / 55$ reduces the deflection and the amount of reinforcements. 


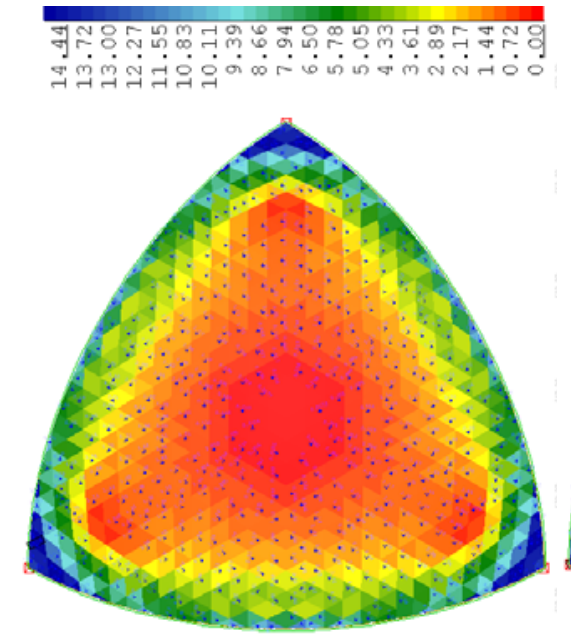

(a) Design 1
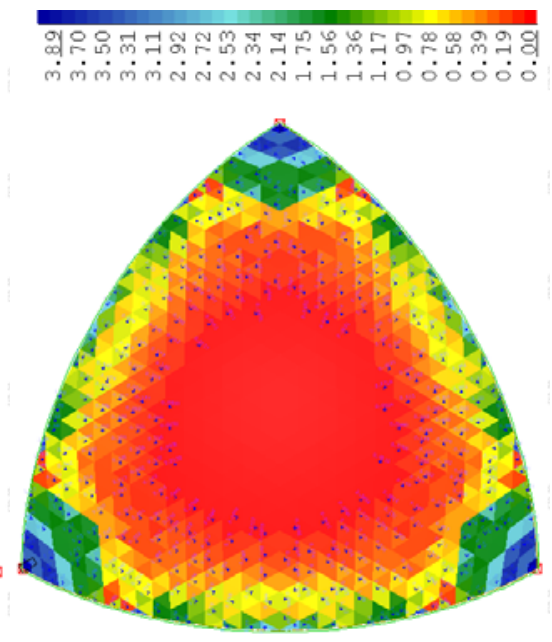

(b) Design 2
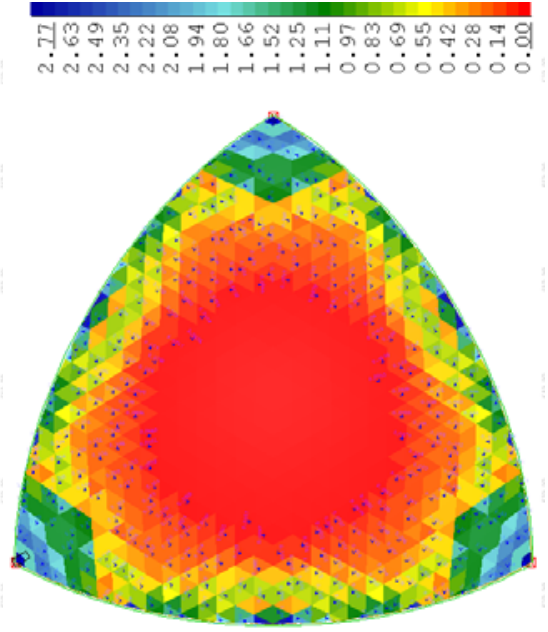

(c) Design 3

Fig. 5 Principal tension stresses in the Kresge shell (for dead load).
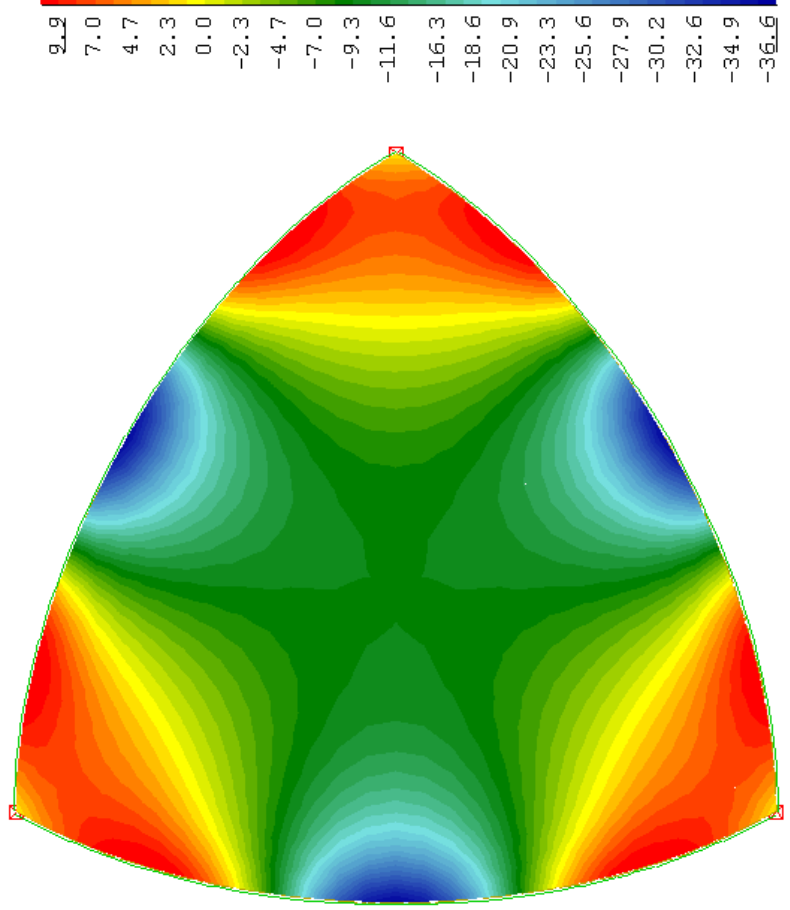

Fig. 6 Downward deflections in the Kresge shell (for dead load).

Table 1 Reinforcements for three shell designs.

\begin{tabular}{lll}
\hline Design & $\begin{array}{l}\text { Top reinforcement } \\
\left(\mathrm{cm}^{2} / \mathrm{m}\right)\end{array}$ & $\begin{array}{l}\text { Bottom } \\
\text { reinforcement }\left(\mathrm{cm}^{2} / \mathrm{m}\right)\end{array}$ \\
\hline 1 & 32,87 punching & 39,58 failure \\
2 & 20,56 & 49,75 \\
3 & 7,33 & 13,37 \\
\hline
\end{tabular}

Structural optimization of Evoluon results in a shell with uniform thickness of $8 \mathrm{~cm}$, reinforced with meridional and hoop ribs. The ribbed model built in Sofistik has a $20 \mathrm{~cm} \times 30 \mathrm{~cm}$ ring at the top of the dome around $6.70 \mathrm{~m}$ diameter skylight. Radiating off of the ring beam at the top of the dome are $30 \mathrm{~cm} \times 60 \mathrm{~cm}$ ribs at $7^{\circ}$. Added are two hoop $30 \mathrm{~cm} \times 60 \mathrm{~cm}$ ribs that are located at $6 \mathrm{~m}$, and $12.2 \mathrm{~m}$ from the edge ring. The edge ring at the junction of the upper and lower shell is 40 $\mathrm{cm} \times 60 \mathrm{~cm}$ with a $77 \mathrm{~m}$ diameter. A $60 \mathrm{~cm} \times 80 \mathrm{~cm}$ bottom ring is supported by $80 \mathrm{~cm} \times 80 \mathrm{~cm} \mathrm{~V}$-shaped columns. The lower shell also has two hoop $30 \mathrm{~cm} \times 60$ $\mathrm{cm}$ ribs that are located at $6 \mathrm{~m}$, and $15.4 \mathrm{~m}$ from the edge ring (Fig. 7). The tensile principal stresses are shown in Fig. 8. The maximum tensile (principal) stresses are equal to 14.20 $\mathrm{MPa}$ and 3.21 $\mathrm{MPa}$ for dead load and snow load respectively (dark blue).

The maximum downward deflection in ribbed Evoluon shell occurs at the apex of the dome (Fig. 9). The $\Delta / L$ value is equal to $1 / 635$ which is smaller than 1/300 limit used by Isler.

\subsection{Shape Optimization}

The effects of the shell rise are also obtained via free optimization. The values for diameter (span) and thickness of Ehime shell are kept constant in the shape 


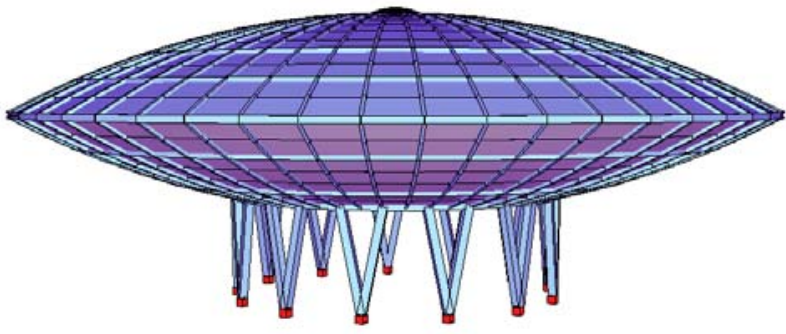

Fig. 7 Ribbed model of Evoluon shell built in Sofistik.

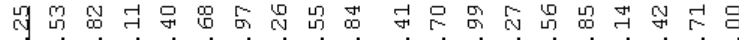
मु

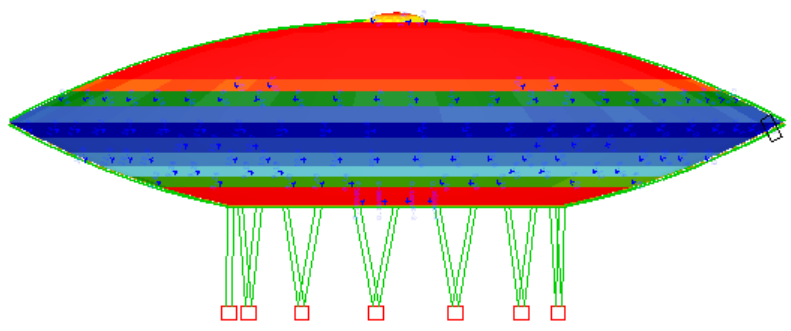

Fig. 8 Principal tension stresses in the ribbed Evoluon shell (for dead load).
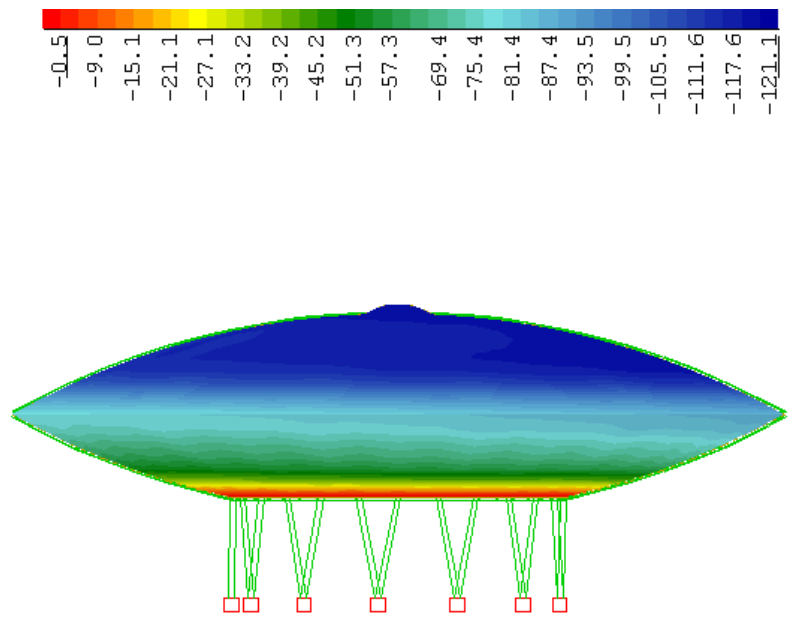

Fig. 9 Downward displacements in the ribbed Evoluon shell (for dead load).

optimization designs. The dimensions of the ring and columns are assumed equal to $40 \mathrm{~cm} \times 60 \mathrm{~cm}$ and 50 $\mathrm{cm} \times 50 \mathrm{~cm}$, respectively. The slope of the shell is set equal to $2^{\circ}$. The only variable that is changed is rise $d$. The rise $\mathrm{d}$ varies from 7,8 and 9 meters in this study. The effects of $d$ on the maximum tensile (principal) stress, downward displacement and reinforcement for a spherical shell with a uniform thickness of $8 \mathrm{~cm}$ are examined. It is seen that the maximum tensile principal stress, downward deflection and reinforcement decrease with $d$. Increasing the rise by circa cca $30 \%$ decreases the maximum tensile principal stresses, the deflections and the reinforcements by $23 \%, 34 \%$ and $20 \%$, respectively.

The shell with $d=7 \mathrm{~m}$ as in original design for Ehime shell has $\Delta / L$ value equal to $1 / 8,812$ which is significantly smaller than $1 / 300$ imposed by Isler.

If the larger distance between the supporting columns had been assumed, the shell would have greater maximum tensile (principal) stress, downward deflection and reinforcement.

Also, our structural optimization study of spherical domes has shown that as the ring size (stiffness) increases, it „keeps” more of the tension, and in the limit case where the area of ring is equal to $\infty$, the system becomes a fixed dome with the small maximum tensile principal stress and reinforcement. In the other direction as the ring size (stiffness) decreases, the dome maximum tensile principal stress and reinforcement increase substantially.

Fig. 10 shows the areas of maximum tensile principal stress in the Ehime dome. The red color represents the area with no tension. It can be seen that bending moments and tensile principal stresses are

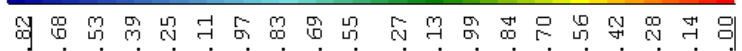
n $x$ a $x$ a

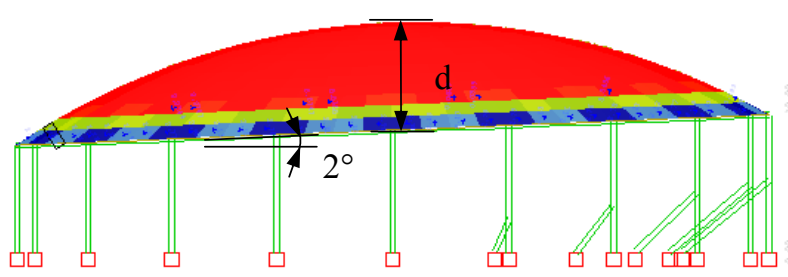

Fig. 10 Areas of tension (based on principal stress) in the Ehime dome (for dead load). 
restricted to a narrow zone at the edge of the dome. This area becomes smaller as the ring size increases.

\section{Buckling of Spherical Shells}

Here an approach which takes into account the large deflection and plasticity effects was performed using Sofistik software to estimate the buckling load.

An analysis according to the third-order theory which contains non-linear analysis plus analysis according to the second-order theory and additionally the effects of the geometrical system modification, e.g., snap through, length modification for big deformations, and behaviour after buckling was conducted. Non-linear effects (e.g. plasticizing and cracks) can be analysed only with iterations, and this is done in Sofistik software with a modified Newton method with constant stiffness matrix.

\subsection{Geometrically Non-Linear Analysis}

An ultimate load iteration in geometrical non-linear analysis of these structures with and without imperfections was performed. To take into account the possible plastification of the material an analysis with non-linear material can also be performed simultaneously with the geometrically non-linear analysis.

Using the stress state of the snow load case the buckling mode shapes are determined considering the element stresses on undeformed system. The first buckling mode shape is applied scaled as non-stressed imperfection (Fig. 11). The imperfection has here a maximum value in global $\mathrm{X}$ direction of $20 \mathrm{~mm}$.

The effects of the shell rise on the value of the critical buckling load are also analyzed for the Ehime shell with and without imperfection. Table 2 gives the effects of rise $d$ on the buckling load factor for a spherical shell with a uniform thickness of $8 \mathrm{~cm}$. It is seen that if the actual radii are larger (that is, the shell is flatter), the membrane forces are generally greater. Hence the value of the buckling load will be lower, possibly substantially lower. Increasing the rise by

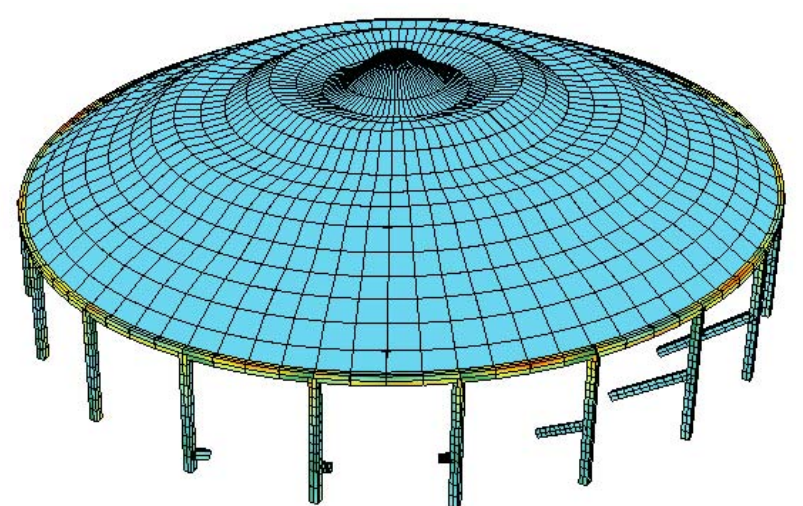

Fig. 11 First buckling shape of Ehime dome applied scaled as non-stressed imperfection.

Table 2 Effect of rise $d$ on buckling load factor for Ehime dome under snow load.

\begin{tabular}{lll}
\hline Rise d (m) & $\begin{array}{l}\text { System without } \\
\text { imperfection }\end{array}$ & $\begin{array}{l}\text { System with } \\
\text { imperfection }\end{array}$ \\
\hline 7 & 48,30 & 19,10 \\
8 & 64,00 & 25,50 \\
9 & 80,30 & 37,10 \\
\hline
\end{tabular}

circa $30 \%$ increases the buckling load factor by a factor of about 2.

Typically, applying initial geometrical imperfection related to the first buckling mode, the buckling load knocks down by a factor of about 2.5 .

In addition, it is seen that the compressive hoop forces of the Ehime dome under snow load change to tension when geometrical imperfection in form of the first buckling mode shape with a maximum deviation of $20 \mathrm{~mm}$ occurs. Since this initial geometrical imperfection leads to tension in hoop direction it is mandatory to include this possibility in the layout of the steel reinforcement of the shell. It should be noted that such observation is not verified on the Ehime dome with rise $d=9 \mathrm{~m}$.

\subsection{Interaction of the Nonlinearities}

The analyzed concrete spherical shells are also used to demonstrate the interaction of the two main nonlinearities, material and geometrical.

An analysis with nonlinear material was performed simultaneously with a geometrically nonlinear analysis. 
Table 3 Buckling load factor for spherical shells.

\begin{tabular}{|c|c|c|c|}
\hline Name of construction & $\begin{array}{l}\text { Without imperfection Geom. } \\
\text { nonlinear }\end{array}$ & $\begin{array}{l}\text { With imperfection Geom. } \\
\text { nonlinear }\end{array}$ & $\begin{array}{l}\text { Without imperfection Geom. } \\
\& \text { mat. nonlinear }\end{array}$ \\
\hline Kresge A. Design 1 & 2,70 & 3,90 & 0,78 \\
\hline Kresge A. Design 2 & 8,00 & 8,20 & 0,72 \\
\hline Kresge A. Design 3 & 14,80 & 15,20 & 1,29 \\
\hline Het Evoluon & 67,70 & 46,10 & 1,05 \\
\hline Ehime Hall & 48,30 & 19,10 & 9,04 \\
\hline
\end{tabular}

The buckling load obtained by a geometrically nonlinear analysis and a combination of geometrically and materially nonlinear analysis of spherical shells is given in Table 3.

From the Table 3, the following conclusions can be drawn: Including only one kind of nonlinearity does not give a realistic situation and their combination results in the decreasing ultimate (failure) load.

\section{Conclusions}

The finite element analysis in this paper demonstrates that structural optimization leads to a more efficient design of the analyzed concrete spherical shells and that such a tool is useful for designing thin shell concrete structures.

A detailed structural optimization study of Kresge Auditorium shows that varying the thickness of the shell, with the largest thickness at the supports, leads to the most effective design in terms of reduced tensile stresses, reduced deflections, and most efficient use of material. It can be concluded that a distributed thickness is appropriate for this design. The results also indicate that the Kresge shell could have been designed with the edge beam of varying cross section and higher concrete strength than the documented C30/37 (4000 psi) strength in order to reduce the excessive deflections. Structural optimization results of Evoluon indicate that the shell could have been designed as a ribbed model that would be less thick to reduce the weight. The shape optimization study of Ehime shell shows that the shell rise could have been larger than 7 $\mathrm{m}$ original design (flatter shell). If the larger distance between the supporting columns had been assumed, the shell would have greater tensile stress, deflection and reinforcement. Note that the structural optimization of these structures could be conducted using the most sophisticated structural optimization techniques available today.

From a detailed structural buckling assessment of analyzed concrete spherical shells it can be concluded that shells can be extremely sensitive with respect to slight deviation of its ideal parameters like its initial geometry, boundary conditions etc. The more realism is taken into account like geometrical imperfections, material nonlinearities, edge effects which cause bending etc., the less prone the shell is to fail by a sudden brittle buckling phenomenon.

\section{References}

[1] SOFiSTiK Team, Sofistik Software (Version 2010), 2010.

[2] E. R. Ford, The Details of Modern Architecture: 1928 to 1988 (Vol. 2), The MIT Press, Cambridge, Massachusetts, 2003, p. 448.

[3] H. Rile, Spatial Roof Structures, Civil Engineering Book, Belgrade, 1977, p. 488. (in Croatian)

[4] International Website of Home Page, available online at: http://www.engr.psu.edu/ae/thinshells/module $\% 20 I I I /$ cas e_study_3.htm (accessed July 5, 2011).

[5] EN 1992-1-1, Eurocode 2: Design of concrete structures, Part 1-1: General rules and rules for buildings, European Committee for Standardization, Brussels, Dec. 2004.

[6] D. P. Billington, The Art of Structural Design: A Swiss Legacy, Princeton University Art Museum, Princeton, New Yersey, 2003, p. 212. 